\title{
Travmatik Diafragma Rüptürü Olan Bir Vakada Rastlantısal Tespit Edilen Perikardial Rüptür ve Kalp Herniasyonu
}

\author{
Incidentally Diagnosed Pericardial Rupture and Herniation of the Heart in a Case of Traumatic \\ Diaphragmatic Rupture

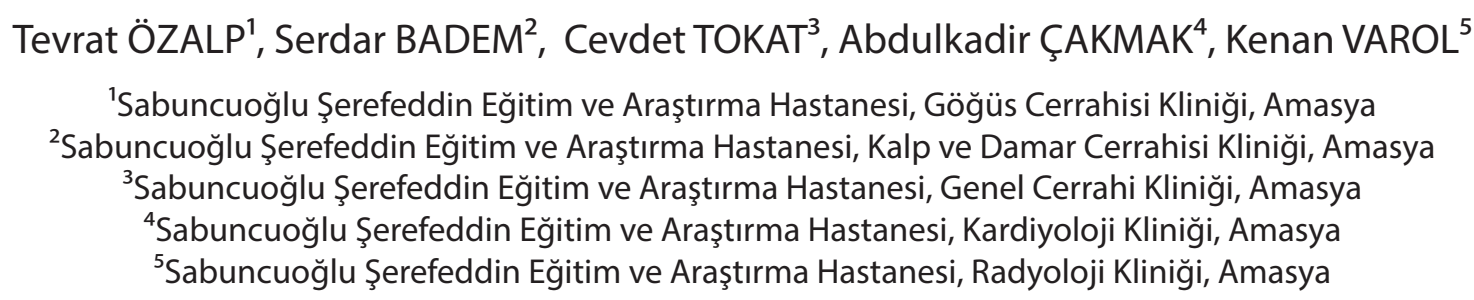

\section{ÖZET}

Perikard ve kalp yaralanmaları travmatik diafragma rüptürüne nadir olarak eşlik eder. Trafik kazası geçiren 42 yaşındaki erkek hastaya diafragma rüptürü teşhisi kondu. Öncelikle laparatomi yapılan hastada, diafragma abdominal yaklaşımla tamir edilmeye çalışıldı. Ancak daha güvenli tamir için yapılan torakotomide perikardın rüptüre olduğu görüldü. Kalp herniye olmuştu. Kalp yerine itildikten sonra perikard ve diafragma primer olarak tamir edildi. Akut diafragma rüptürlerinde ilk yaklaşım genellikle laparotomidir. Ancak abdominal müdahale edilen diafragma rüptürlerinde toraks mutlaka aydınlatılmalı ve intratorasik yapılar her aşamada yakın takip edilmelidir.

Anahtar Kelimeler: Travmatik diyafragmatik herni, perikard rüptürü, kalp herniasyonu.

\section{ABSTRACT}

Pericardium and heart injuries are rare situations accompanying to traumatic diaphragmatic ruptures. We diagnosed diaphragmatic rupture for a 42 year old man after a traffic accident. First, the patient underwent laparotomy and the diaphragmatic rupture was tried to be repair intraabdominally. For more safety repair we decided to perform thoracotomy. This exploration showed that pericardium was ruptured, the heart was herniated. Laparotomy is first choice treatment of acute diaphragmatic ruptures. However, thorax must be lightened absolutely in the diaphragmatic ruptures which repaired intraabdominally and intrathoracic organs must be evaluated closely in every step.

Keywords: Traumatic diaphragmatic hernia, pericardial rupture, herniation of hearth. 


\section{GíRiş}

Diafragma; abdominal ve torasik kavitelerini ayıran, anatomik lokalizasyonu ve dinamik fonksiyonu nedeniyle çok nadiren tek başına yaralanabilen bir organdır. Akut olgularda, ek organ yaralanmaları nedeniyle cerrahi yöntem genellikle laparatomidir (1). Birlikte yaralanan organlar dalak, karaciğer ve diğer içi boş organlar olmakla birlikte çok nadir olarak perikard ve kalp yaralanmaları da görülmektedir (2). Bu vakayı sunmamızdaki amaç; diafragma rüptürüne yönelik özellikle intraabdominal olarak yapılan müdahalelerde, toraksın mutlaka aydınlatılması ve her aşamada takip edilmesi gereğini vurgulamaktır.

\section{OLGU SUNUMU}

Trafik kazası nedeni ile hastanemiz acil polikliniğine getirilen 42 yaşındaki erkek hastada kan basıncı $90 / 60$ mmHg, nabız 100/dk, solunum sayısı 18/dk, sO2\%92.8 olarak ölçüldü. Nefes darlığı ve göğüs ağrısı olan hastanın fizik muayenesinde; her iki hemitoraks ağrılı, hassas, sol akciğer bazalde solunum seslerinde azalma görüldü. Batın muayenesinde ise palpasyonla sol üst batın bölgesinde hassasiyet, rebound ve defans tespit edildi. Akciğer PA grafisinde; sol diyaframın yukarı seviyede ve hemotoraks ile uyumlu opasite artışı görüldü (Şekil 1). Hastaya

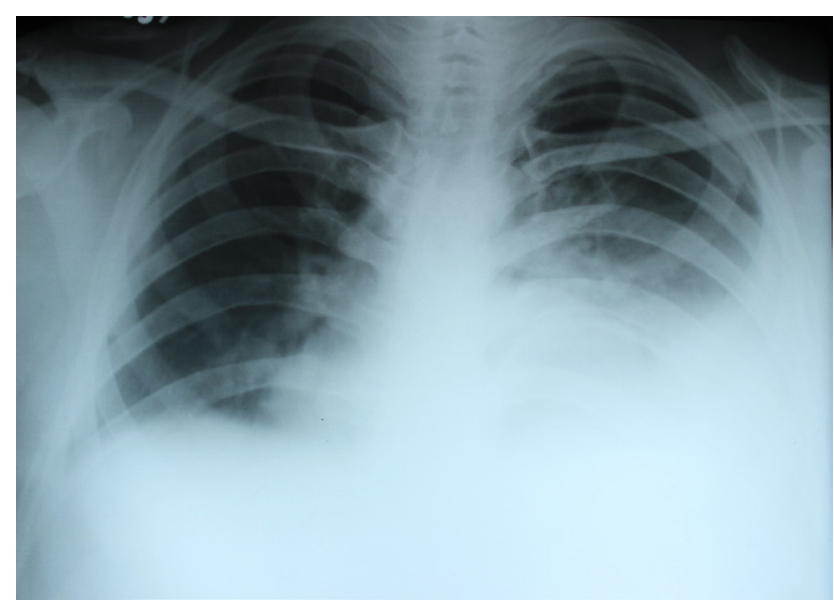

Şekil 1: Preop PA akciğer grafisi.

çektirilen toraks-üst batın tomografisinde; bilateral hemotoraks, dalak, barsak, mide ve pankreasın toraksa herniasyonu ile uyumlu görünüm izlendi (Şekil 2 ve 3). Laboratuar analizlerinde hemoglobinin $10 \mathrm{gr} / \mathrm{dl}$ olması dışında herhangi bir anormallik tespit edilmedi. Diafragma rüptürü, bilateral hemotoraks, sol
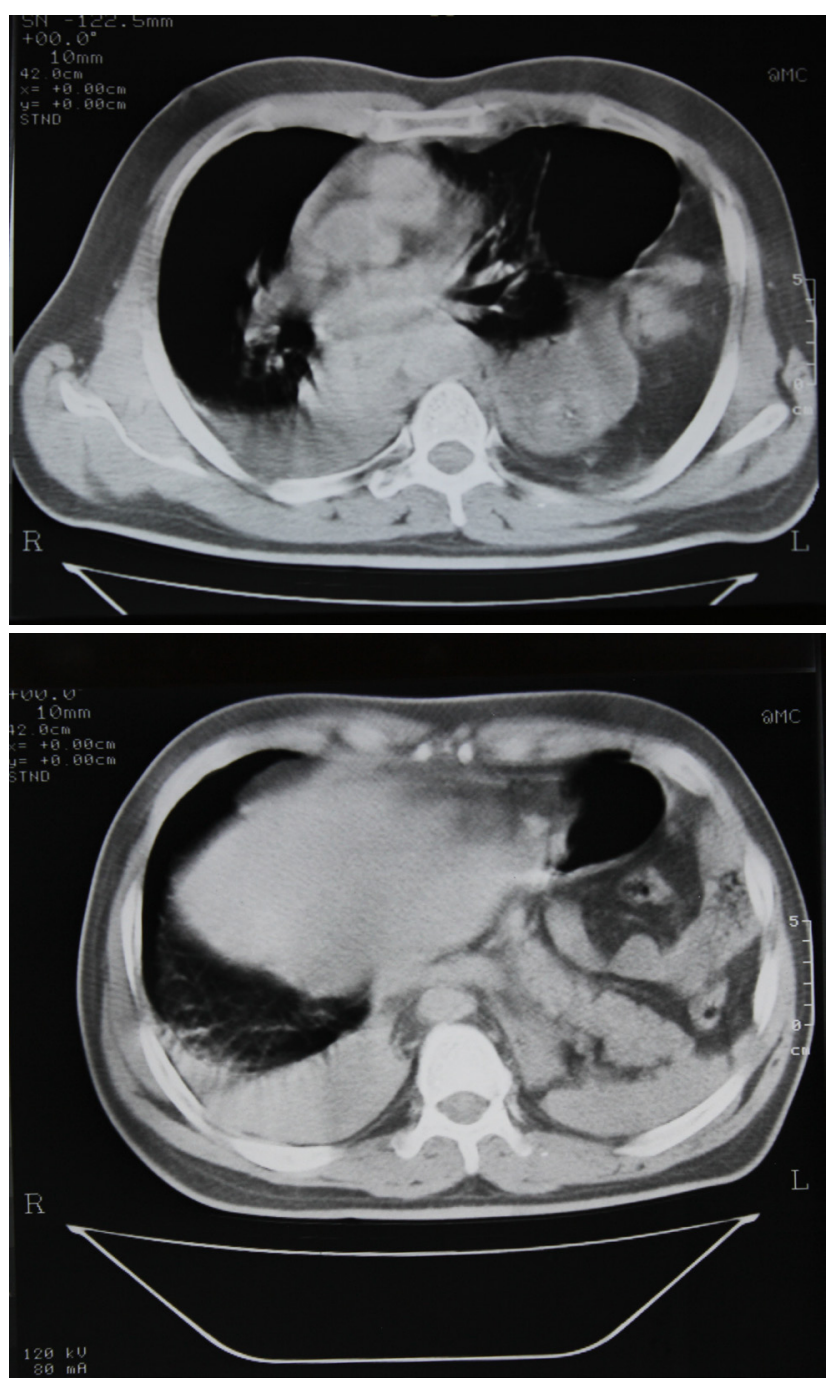

Şekil 2 ve 3: Toraks bilgisayarlı tomografide; bilateral hemotoraks, dalak, barsak, mide ve pankreasın toraksa herniasyonu ile uyumlu görünüm izlenmektedir.

multipl kosta fraktürü ve mandibula fraktürü teşhisi ile hasta ameliyathaneye alındı. Sağ ve sol tüp torakostomi uygulanan hastada, ilk anda sağ tüp torakostomiden $500 \mathrm{cc}$ hemorajik drenaj oldu. Sol tüp torakostomiden ise az miktarda hemorajik drenaj olması üzerine müdahalenin abdominal yaklaşımla olmasına karar verildi.

Genel anestezi altında, supin pozisyonu bozulmadan yapılan laparotomide; diafragmanın totale yakın rüptüre olup dalak, mide, ince barsağın ve kısmen pankreasın toraks içine herniye olduğu görüldü. Organlar batına çekilerek splenektomi yapıldı. Diafragmatik yırtığın gerek büyük ve gerekse posteriorda ösofagusa kadar uzanması nedeniyle, daha güvenli tamir ve ekspojur için torakotomiye karar verildi. Müdahalenin bu kısmına kadar nabız (80-95/dk, ritmik) ve tansiyon arteriyeli $(120 \backslash 70 \mathrm{mmHg})$ normal 


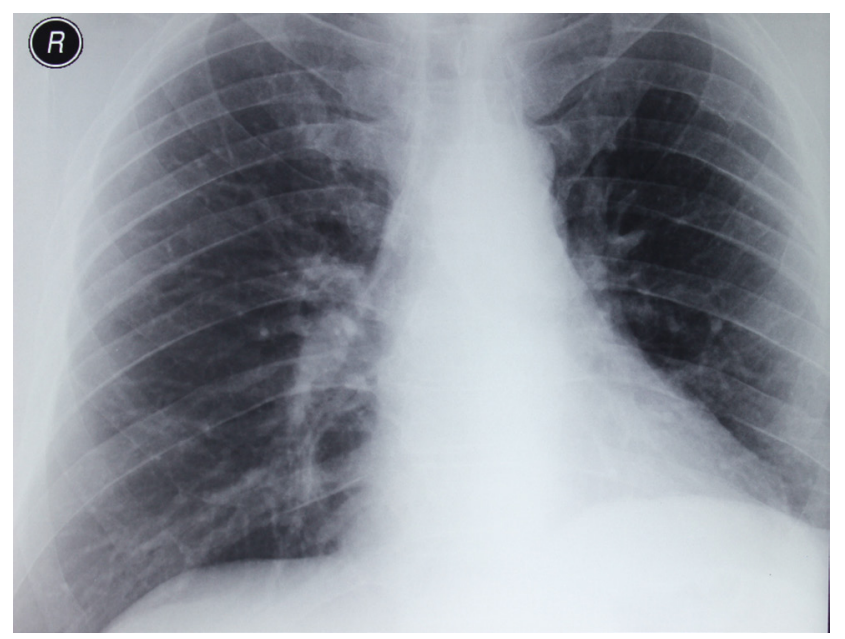

Şekil 4: Operasyondan 1 yıl sonra.

sınırlarda seyretti. Yapılan sol anterolateral torakotomide belli bir kanama odağı yoktu. Ancak perikardın rüptüre olduğu görüldü. Kalp perikarddan herniye olmuştu ve bradiaritmikti (30) $\mathrm{dk}$ ). Kalp yerine itilerek perikard tamir edildi ve perikardiyal pencere bırakıldı. Ritmin normale döndüğü görüldü. Diafragma, no:1 prolen ile iki kat olarak matress dikişlerle primer tamir edildi. Ayrıca torasik aorta trasesinde hematom tespit edilen hastada intramural hematom düşünülerek konservatif kalınması kararlaştırıldı. Postoperatif dönemi sorunsuz geçen hasta şifa ile taburcu edildi. Kontrollerinde yapılan kalp EKO'sunda, minimal perikardial efüzyon haricinde bir patoloji gelişmedi. Hastanın bir yıl sonra yapılan kontrolünde muayene bulguları normal olup, sol akciğer ekspanse olup sol diafragma izlenmekteydi (Şekil 4).

\section{TARTIŞMA}

Diafragma rüptürü majör travmalı hastalarda \% 3-8 oranında görülmektedir. Künt diafragma yaralanması bulunan olguların \%80-100'ünde ek bir extra abdominal organ yaralanması, \%5080 'inde ise intraabdominal organ yaralanması görülebilir. Bu tür travmalarda diafragma yaralanmasına en çok intrakranial hasar, pelvis fraktürleri, extremite fraktürleri, kosta fraktürleri, dalak, karaciğer eşlik eder (3). Diğer organ hasarlarının varlığı, yapılacak ilk müdahale şeklini etkileyecektir. Çünkü ek organ hasarları mortalitenin yüksek olmasına neden olur. Travmatik diafragma rüptürlerine kardiak ve perikardial yaralanmalar da eşlik edebilmektedir ve bunlar beraber görülen en nadir yaralanmalardandır (1).
Travmatik diyafragma yaralanmalarının tanısında PA akciğer grafisi, abdominal USG, floroskopi, torako-abdominal CT, MR, dalak ve karaciğer sintigrafileri, torakoskopi ve laparoskopi gibi incelemeler gerektiğinde başvurulacak diğer tanı yöntemleri olmalıdır. Travmatik diafragma yaralanmalarının tanı ve tedavisinde VATS (Video-Assisted Thoracic Surgery) hemodinamisi stabil olan hastalarda güvenilir bir yöntem olarak artan sıklıkta kullanılmaktadır.

Hipovolemik olup durumu stabil olmayan hastaların lateral veya semilateral pozisyona çevrilmesi tavsiye edilmez. Mümkün olduğu kadar supin durumları korunmalıdır.

Diafragma hasarlarının etkili tedavisi hasarın cerrahi olarak onarımıdır. Diafragma rüptürü teşhisi konan acil vakalarda, organ yaralanmasının veya kanamanın düşünüldüğü taraf cerrahi olarak önceliklidir. Cerrahi girişim yapılırken, hastanın sahip olduğu ilave patolojiler, diyafram yaralanmasının lokalizasyonu ve büyüklüğü göz önüne alınmalıdır. Akut olgularda genellikle cerrahi yöntem laparotomidir (1). Ancak diafragmanın tamirinin en iyi ekspojurunu torakotomi sağlar. Torakotomiden dalağa yönelik tamir ya da splenektomi uygulanabilir olmasına rağmen batın ekspojuru açısından tam güvenilir değildir. Buna göre hastaya laparotomi, torakotomi veya her ikisi birlikte yapılabilir (1).

Perikard rüptürlerinde kalp herniasyonu gelişebilir. Perikard rüptürü kalp defektten herniye olmadıkça veya hemoraji gelişmedikçe genellikle semptomsuzdur. Perikard rüptürü sonucunda gelişen kardiyak herniasyon, vasküler yıkım ve ani ölüme neden olabileceği için cerrahi olarak tamir edilmelidir (4). Olgumuzda perikard rüptürü ve kalp herniasyonu ameliyat sırasında saptandı. İlkönce laparotomi yapılan olgumuzda diyafragmanın, intraabdominal sahadan tamiri uygun görülebilirdi. Ancak, yırtığın büyük olması, santral tendonu da içine alarak özefagusa kadar uzaması, tamir için bize güvenli bir ekspojur sağlamadı. Bunun için torakotomi tercihi yapıldı ki perikard rüptürü ve kalp herniasyonu bu sırada saptandı. İntratorasik yaralanma ses- 
siz seyredebilir ve hayati öneme sahiptir. Tanı koymak zordur ve genellikle intraoperatif konulabilir (4).

Sonuç olarak; künt travma sonrası diyafram ve perikard rüptürleri kolayca gözden kaçabilmektedir. Travma sonrası bu rüptürlerin gelişebileceğinin akılda tutulması tanının en önemli aşamasını oluşturur (5). Özellikle abdominal yaklaşımla tamirinin tercih edildiği künt travmatik diafragma rüptürlerinde, gerek peroperatif ve gerekse postoperatif dönemde bile perikard rüptürleri mutlaka akılda tutulmalıdır. İntratorasik yapılar her aşamada dikkatle izlenmelidir. Tanı konulduğunda ölümcül komplikasyonlar gelişmeden cerrahi ile tamir yapılmalıdır.

\section{KAYNAKLAR}

1. Şehitoğulları A, Sayir F, Kahraman A, ve ark. Diafragmanın travmatik yaralanmaları. Dicle Tıp Dergisi 2012;39(2):257-61.

2. Çobanoğlu U, Kara V, Yalçınkaya İ, ve ark. Traumatic diaphragmatic ruptures: diagnostic and therapeutic approaches. Türk Göğüs Kalp Damar Cerrahisi Dergisi 2012;20(1):85-93.

3. Akgün Y, Aban N, Taçyıldız I ve ark. Blunt Diaphragmatic Injuries. Ulusal Travma Dergisi 1996;12(2):15-21.

4. Khalpey Z, Rajab TK, Schmitto JD ve ark. Traumatic pericardial rupture with skeletonized phrenic nevre. J Cardiothorac Surg 2011;6(6):1186-90.

5. Arslan $E$, Işık $A F$, Şanlı $M$ ve ark. Künt travmanın nadir komplikasyonu; Çocuk olguda diyaframperikard rüptürü ve kardiyak herniasyon. Ulusal Travma Acil Dergisi 2013;19(4):363-5. 